\section{Third of EEA qualified dentists may leave UK after Brexit}

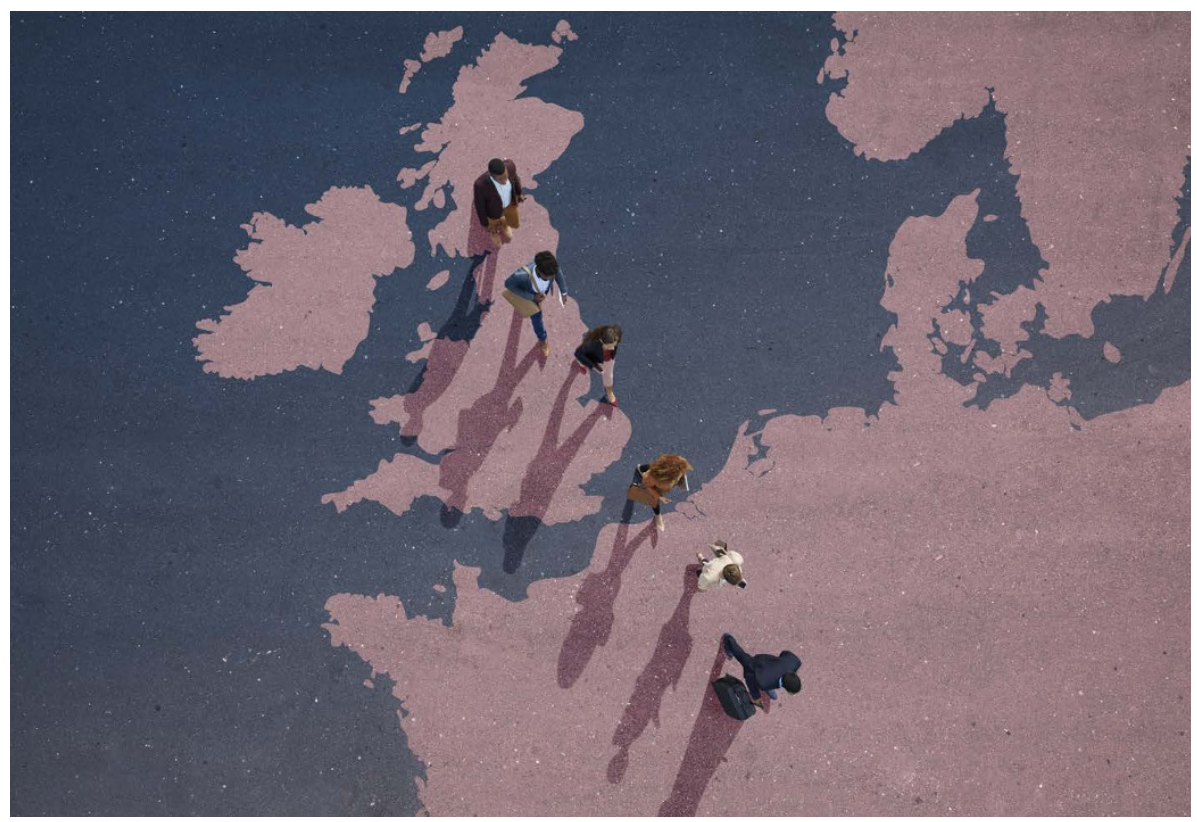

A round a third of dentists who qualified in Europe but who currently work in the UK say they are considering leaving the UK, largely because of Brexit.

The UK's imminent departure from the European Union (EU) in March 2019 looks likely to have a significant impact on the dental workforce, according to a survey of almost 2,500 dentists working here who were trained in the European Economic Area (EEA).

The BDA said the findings underlined the need for ministers to acknowledge problems in dentistry in the face of such a potential exodus of dentists from the NHS.

Dental regulator, the General Dental Council (GDC), published a report ${ }^{1}$ on 22 January 2019 on the post-Brexit intentions of EEA-qualified dental professionals based on independent research that it commissioned from Enventure Research, a market research agency specialising in the public sector.

The report contains details of an online survey issued to all European qualified dental professionals on the GDC register (approximately 6,300 registrants). Over a four week period in June and July 2018, 2,464 registrants completed the survey. In addition, ten in-depth interviews were carried out.

Responses showed that almost a third $(32 \%)$ of those surveyed said they were considering leaving the UK in the next few years, although more than half (55\%) of this group said this might change if their qualifications continued to be recognised.

Of those intending to leave, $82 \%$ said that Brexit and the uncertainty about arrangements for EU citizens living and working in the UK was a significant factor in their reasoning.

The vast majority (84\%) agreed that Brexit was leading to a shortage of healthcare workers in the UK and 75\% agreed that it was leading to a shortage of dental professionals.

More than half of European qualified dental professionals who responded to the survey said they came to the UK for work (55\%) while $27 \%$ came for family reasons.

Many interview participants said they had come to the UK originally to work largely for economic reasons (better pay) and because there were many posts available, but a few had also come for personal or family reasons.

Interview participants thinking of leaving the UK were mainly considering relocating to their country of origin or another English speaking country even though some of these participants conceded they might earn less money in other countries or struggle to find a job.

Others thought that rising wages and shortages of dental professionals in other European countries might make them more attractive than in the UK, particularly given the fall in the value of the pound following the EU referendum on the UK leaving the EU held in 2016.

The GDC said it felt it was important to gauge the opinions of overseas dentists given that almost a fifth of UK dentists (and around the same proportion of new applicants to the professional register each year) qualified in the EEA.

Head of Regulatory Intelligence at the GDC, David Teeman, said: 'Exploring the intentions of people who are currently able to work in UK healthcare because their qualifications are recognised under EU legislation is essential.

'This research was undertaken before important issues have been resolved, such as recognition of qualifications, residency rights and access to the UK for existing and prospective dental professionals.

'Once these issues are settled, we are planning a further round of research which will aim to provide us with increased insight and aid us in our planning. We recognise the information could be useful to others, for example those involved in workforce planning, and will therefore be making it publicly available also.'

The BDA said the survey findings showed there was a workforce crisis in dentistry and although registrant numbers had remained broadly stable since Brexit was decided upon, the BDA had expressed its deep concerns that government has so far been unwilling to engage on growing recruitment and retention problems.

BDA Chair Mick Armstrong said: 'Government has failed to even acknowledge the scale of the crisis that's been facing dentistry for several years. Broken NHS contracts, rock bottom morale and now Brexit are all taking their toll.

'The writing is now on the wall for too many European and UK qualified dentists. Government needs to wake up, and smell the coffee. NHS dentistry can't be run without dentists.'

1. General Dental Council. Survey of European Qualified Dental Professionals Final Report. 2019. Available at https://www.gdc-uk.org/about/what-we-do/research (accessed January 2019). 